\title{
Dietary, behavioural and socio-economic determinants of the metabolic syndrome among adults in Luxembourg: findings from the ORISCAV-LUX study
}

\author{
Ala a Alkerwi $^{1,2, *}$, Anne-Françoise Donneau ${ }^{2}$, Nicolas Sauvageot $^{1}$, Marie-Lise Lair ${ }^{1}$, \\ Adelin Albert ${ }^{2}$ and Michèle Guillaume ${ }^{2}$ \\ 'Centre de Recherche Public Santé (CRP-Santé), Centre d'Etudes en Santé, Grand-Duchy of Luxembourg, 1A rue \\ Thomas Edison, L-1445 Strassen, Luxembourg: ${ }^{2}$ School of Public Health, University of Liège, Liège, Belgium
}

Submitted 21 March 2011: Accepted 29 July 2011: First published online 14 September 2011

\begin{abstract}
Objective: The purpose of the present research was to investigate the epidemiological profile of the metabolic syndrome (MetS) and to explore its potential dietary, behavioural and socio-economic determinants among European adults residing in Luxembourg.

Design: Cross-sectional, population-based ORISCAV-LUX survey.

Setting: European adults aged 18-69 years residing in Luxembourg.

Subjects: A total of 1349 Europid adults, who participated in the ORISCAV-LUX survey, were included in the study. The prevalence of MetS was estimated according to the Revised-Adult Treatment Panel (R-ATPIII) criteria. Multivariate logistic regression was used to identify the dietary, behavioural and socioeconomic factors independently associated with MetS.

Results: The overall prevalence of MetS was $24.7 \%$ with significant gender difference (18.5\% for women $v .30 \cdot 8 \%$ for men, $P<0 \cdot 0001$ ). Age, male gender, primary level of education, physical inactivity, family history of diabetes and hypertension and inadequate protein intake were identified as significant determinants of MetS, after adjusting for other socio-economic, family medical history and lifestyle factors. Conclusions: MetS is a common condition among Europid adults in Luxembourg and increases dramatically with age, in both genders. Several dietary, socio-economic and behavioural factors explain the disparity observed. These findings highlight the importance of a comprehensive approach to MetS encompassing dietary, lifestyle and socio-economic aspects, both in clinical and community settings.
\end{abstract}

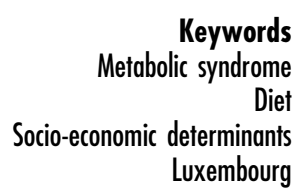

The metabolic syndrome (MetS) represents a clustering of central adiposity, dyslipidaemia, hyperglycaemia and elevated blood pressure, being associated with an increased risk of CVD and type 2 diabetes ${ }^{(1-3)}$. Although its pathogenesis is still incompletely understood, the interaction of obesity, a sedentary lifestyle and dietary, genetic, socio-economic and environmental factors is known to contribute to its development ${ }^{(4,5)}$.

Increasing evidence indicates that the distribution of MetS varies remarkably among different geographic and socio-economic categories of the population, demonstrating notable health inequalities. Unhealthy behaviours are substantially responsible for epidemic prevalence of diabetes, metabolic disorders and cardiovascular mortality ${ }^{(6,7)}$. In contrast, a healthy lifestyle including non-smoking, an appropriate diet, satisfactory physical activity level and a healthy weight can provide substantial cardiovascular and metabolic benefits ${ }^{(8)}$.
Most of the evidence regarding socio-economic and lifestyle determinants of MetS have come from American ${ }^{(9-12)}$ and Asiatic settings ${ }^{(13,14)}$ and from southern European countries $^{(15,16)}$. However, these findings were inconsistent owing to diversity in the populations' characteristics, the criteria used to define MetS, the methodologies of data collection and the selection of confounding factors. Knowledge and understanding of the epidemiological profile of this emerging pathology is an essential prerequisite to assess public health needs and to address population-specific, evidence-based prevention strategies.

Luxembourg is a small country situated in the heart of Europe, hosting foreign residents from over 150 different nationalities, predominantly of European origin. Cardiovascular mortality accounted for about $40 \%$ of total causes of death in $2006^{(17)}$. A recent study, based on a representative sample of the adult residents in Luxembourg (ORISCAV-LUX), confirmed high prevalences of diabetes, 
hypertension and lipid disorder, the major components of $\mathrm{MetS}^{(18)}$. Additionally, the multiple-risk profile was more prevalent in men than in women, even in younger age groups. These initial findings fostered novel research work to estimate the overall, age- and gender-specific prevalence of MetS and to explore the potential dietary, socio-economic and behavioural factors that may determine the prevalence variations.

The recent guidelines released by the Joint Interim Statement (JIS) 2009 stressed the need to adopt ethnicspecific values of waist circumference (WC) to define MetS. For the Europid population, dual WC references, $94 / 80 \mathrm{~cm} v \cdot 102 / 88 \mathrm{~cm}$ for men and women, respectively, were suggested ${ }^{(19)}$. The comparison of the various MetS definitions, carried out on European adults of the ORISCAVLUX study ${ }^{(20)}$, demonstrated an 'almost perfect' level of agreement between the JIS (94/80) and the Revised-Adult Treatment Panel (R-ATPIII; 102/88) definitions. Given that the prevalence of MetS varies considerably across ethnic groups $^{(21)}$, the purpose of the present study was to identify the dietary, behavioural and socio-economic determinants of MetS among the adult Europid population residing in Luxembourg using the R-ATPIII criteria.

\section{Methods}

\section{Study population}

ORISCAV-LUX is a nationwide, cross-sectional survey, conducted between November 2007 and January 2008, to study cardiovascular risk factors among the presumably healthy adult residents of Luxembourg. A representative random sample of 4496 individuals, stratified by sex, age (18-69 years) and district of residence, was selected from the national health insurance registry. Pregnant women ( $n$ 21), people living in institutions ( $n$ 12), people with serious mental and/or physical handicap ( $n 5)$, prisoners ( $n 1)$, people outside the determined age range $(n 2)$ and those deceased before recruitment ( $n 5$ ) were excluded. Overall 3018 individuals did not participate in the study, including invalid addresses ( $n$ 213), negative answers ( $n$ 502), withdrawal cases ( $n$ 80), non-respondents ( $n$ 2192) and those could not participate ( $n$ 31). Ultimately, a total of 1432 participants completed the recruitment procedure including 1349 (94.2\%) of European origin. The participation rate corresponded to the theoretically expected rate upon which the sample size was calculated ${ }^{(22)}$. After eliminating missing data in various components of MetS, data from 1319 participants were available for analysis. The predominantly white homogeneous nature of the sample ensured control over the ethnicity factor, hence permitting generalization of the results over the source population. The demographic and socio-economic characteristics of the studied European population were comparable to those of the general ORISCAV-LUX sample. A comprehensive description of the survey design, sampling method and sample representativeness is published elsewhere ${ }^{(18,22)}$. Briefly, selected individuals were invited through a personal letter followed by a telephone contact to attend study centres. An auto-administered questionnaire covered information on demographic, socioeconomic factors (age, gender, country of birth, marital status, income and educational level), physical activity, dietary habits, smoking status, personal medical history, family medical history and current drug therapy. The anthropometric measurements included body height and weight, which were taken on subjects in light clothing without shoes. WC was measured at midway level between the lower rib margin and the iliac crest. Blood pressure was measured at sitting position, after minimum 30 min of rest. Minimum 8-h fasting blood samples were analysed for glucose, HDL cholesterol (HDL-C) and TAG.

All participants were duly informed and consented to take part in the study, which was approved by the National Research Ethics Committee and the National Commission for Private Data Protection.

\section{Definition of metabolic syndrome}

The participants had MetS if three or more of the following R-ATPIII criteria ${ }^{(23)}$ were met: (i) raised TAG $\geq 150 \mathrm{mg} / \mathrm{dl}$ or treatment for this lipid anomaly; (ii) reduced HDL-C $<40 \mathrm{mg} / \mathrm{dl}$ for men or $<50 \mathrm{mg} / \mathrm{dl}$ for women or treatment for this lipid anomaly; (iii) systolic blood pressure (SBP) $\geq 130 \mathrm{mmHg}$ or diastolic blood pressure (DBP) $\geq 85 \mathrm{mmHg}$ or treatment of previously diagnosed hypertension; (iv) fasting plasma glucose (FPG) level $\geq 100 \mathrm{mg} / \mathrm{dl}$ or use of medication for hyperglycaemia; (v) elevated WC $\geq 102 \mathrm{~cm}$ for men or $\geq 88 \mathrm{~cm}$ for women.

\section{Demographic, socio-economic and clinical factors}

The education level was classified into three groups: 'primary', 'secondary' and 'tertiary' level. Marital status was recorded as 'single', 'divorced or separated', 'widowed' and 'married or living with partner'. Work status was classified as 'employed' 'retired' and 'unemployed including sick leaver and disabled'. 'Objective economic status' was ascertained by asking participants to select the category best representing total monthly household income and to indicate the number of adults and children living in the same household, in order to measure the Adult Equivalent Income (AEI). On the basis of the current official national poverty risk threshold for AEI (National Institute of Statistics), the income variable was classified as either above or below risk of poverty threshold. 'Subjective economic status' was assessed by asking 'To what extent do your current income and other available resources allow you to provide for your needs?' and was classified as 'difficult' or 'easy'. Family history of diabetes mellitus, arterial hypertension, myocardial infarction and cerebrovascular accident were considered positive when the participant reported that his/her parents or close relatives had history of the selected medical condition. 


\section{Lifestyle-related factors}

Smoking was categorized as current, former and nonsmoker. The current dose-related tobacco exposure was estimated from the number of cigarettes smoked daily, classified as $<10,10-20$ and $>20$ cigarettes/d. Alcohol intake was dichotomised as drinker or nondrinker. Physical activity across a variety of daily situations (leisure time, work, transport and household tasks) was evaluated by means of the International Physical Activity Questionnaire (IPAQ), which categorizes the population into three levels: 'low' (physically inactive), 'moderate' and 'high' levels of physical activity on the basis of scoring criteria.

\section{Dietary factors}

Dietary intake data were collected using an FFQ which reports the frequency of consumption and portion size of 134 items over the last 3 months. To describe overall quality diet, a Diet Quality Index (DQI) was developed. It comprised thirteen components assessed on the basis of WHO recommendations for the prevention of chronic diseases $^{(24)}$. The DQI evaluates the intake of key dietary elements that must be supplied sufficiently to guarantee a healthy diet. For each achieved component intake goal, one point was attributed; otherwise a zero was given indicating a poor-quality diet. Components 1-4 were based on SFA, PUFA, MUFA and overall fat consumption as a percentage of total daily energy intake. Component 5 measured the ratio of $n-6$ to $n$ - 3 fatty acids. Component 6 was based on cholesterol intake in $\mathrm{mg} / \mathrm{d}$. Components 7-9 were based on total carbohydrates, simple sugars and total protein, respectively, as a percentage of total daily energy intake. Components 10-13 measured $\mathrm{Na}$, fruits/vegetables, and total and soluble fibre intakes in $\mathrm{g} / \mathrm{d}$.

\section{Statistical analyses}

MetS was considered as the dependent variable, while age, gender, marital status, education level, work status, smoking habits, alcohol consumption, physical activity, dietary habits and family history of selected medical conditions were the independent covariates. 'Low risk' participants (younger age, women, non-smokers, nondrinkers, physically active, respect the dietary recommendations, without family history of selected medical conditions) were taken as reference categories. Selection of variables in the multivariate logistic regression analysis was based on a literature review and on statistical criteria (variables showing $P<0 \cdot 10$ were entered in the multivariate model). Non-selected variables were discarded from the final model. The introduction of BMI was tested in another multivariate model.

To account for the stratified random sampling method used to recruit the participants, weighted statistical methods were applied to produce nationally representative estimates. A sampling weight equal to the inverse probability of unit selection was allocated to each participant from the same stratum. This stratum sampling weight was defined as the ratio between the population stratum size and the observed sample stratum size. All statistical analyses were performed using the SAS statistical software package version 9.2 (SAS Institute Inc., Cary, NC, USA). Results were considered to be significant at the $5 \%$ critical level $(P<0 \cdot 05)$.

\section{Results}

\section{Epidemiology of the metabolic syndrome}

The overall prevalence of MetS among the presumably healthy Europid adults residing in Luxembourg was $18.5 \%$ for women and $30 \cdot 8 \%$ for men $(P<0 \cdot 0001)$. For both genders, the MetS prevalence rate increased remarkably with age, ranging from $<1 \%$ among young women to reach a peak of $60 \%$ in elderly men. No interaction with age or with gender was found for MetS (Fig. 1). The salient components in both genders were elevated blood pressure and TAG. The prevalence of each component was significantly higher in men than in women except for abdominal obesity (Fig. 2).

\section{Prevalence of metabolic syndrome and socio-economic factors}

Given the marked increase in MetS prevalence with age and significant gender-specific differences, the effect of each socio-economic characteristic was adjusted for these two factors. The possible interaction of each variable with age and gender was also considered. Table 1 displays the age- and gender-adjusted odd ratios for MetS according to socio-economic characteristics. Except for marital status, there were significant associations between the prevalence of MetS and all selected socio-economic characteristics, namely level of education $(P<0 \cdot 0001)$, work status $(P=0.037)$ and subjective $(P=0.024)$ and objective economic status $(P=0 \cdot 003)$. There was a significant work status $\times$ age interaction.

Regardless of age and gender, subjects with primary and secondary level of education were at more than 2-fold and 1.5-fold increased risk of MetS than those with a university degree $(\mathrm{OR}=2 \cdot 34 ; 95 \%$ CI $1 \cdot 57,3 \cdot 48$ and OR $=1 \cdot 51 ; 95 \%$ CI $1 \cdot 04,2 \cdot 17$ ), respectively.

The prevalence of MetS was significantly lower in employed participants $(19 \cdot 5 \%)$ than in retired $(54.0 \%)$ and non-employed participants, including sick leavers and disabled $(37.7 \% ; P=0.037)$, with an interaction effect of age. Considering housewife status as a separate risk factor, non-working women had a significantly higher prevalence of MetS $(P<0 \cdot 0001)$ and a twofold increased risk $(\mathrm{OR}=2 \cdot 40 ; 95 \%$ CI $1.51,3 \cdot 80)$ compared with working women, even after age adjustment. 


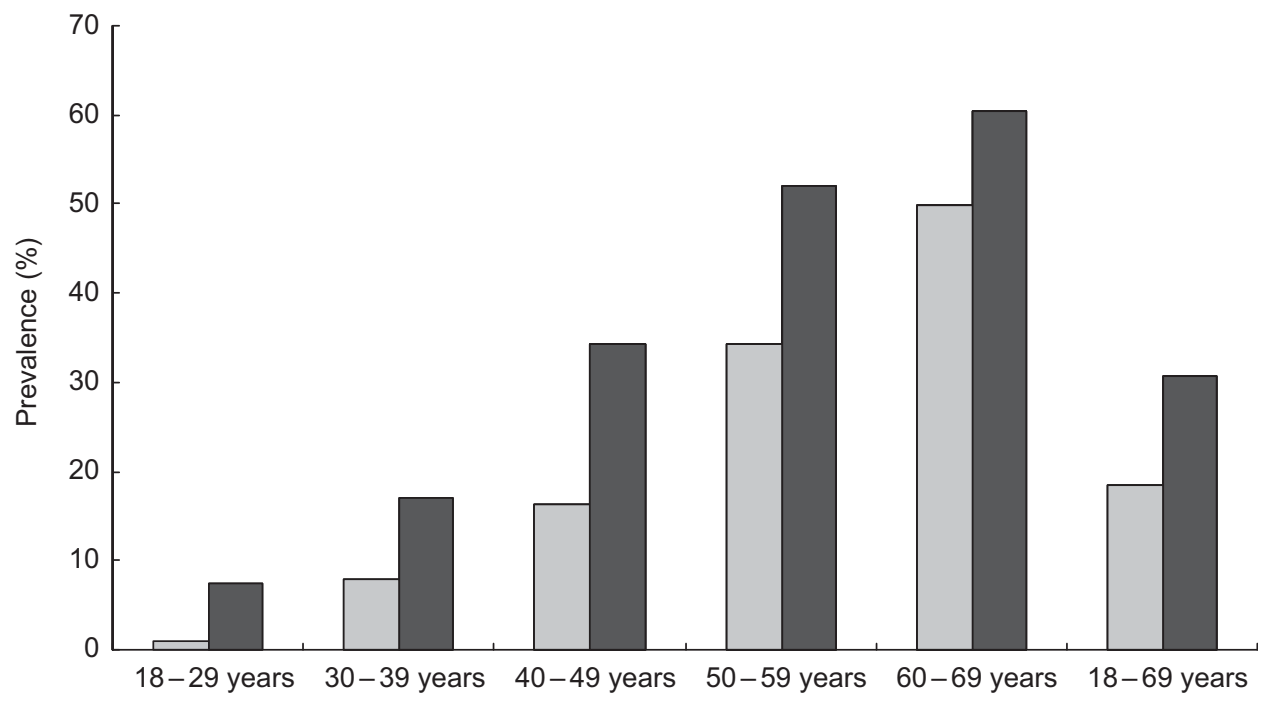

Fig. 1 Gender- and age-specific prevalence of the metabolic syndrome, according to the Revised-Adult Treatment Panel (R-ATPIII) definition, among the European adult residents of Luxembourg, ORISCAV-LUX study ( $\square$, women; $\square$, men)

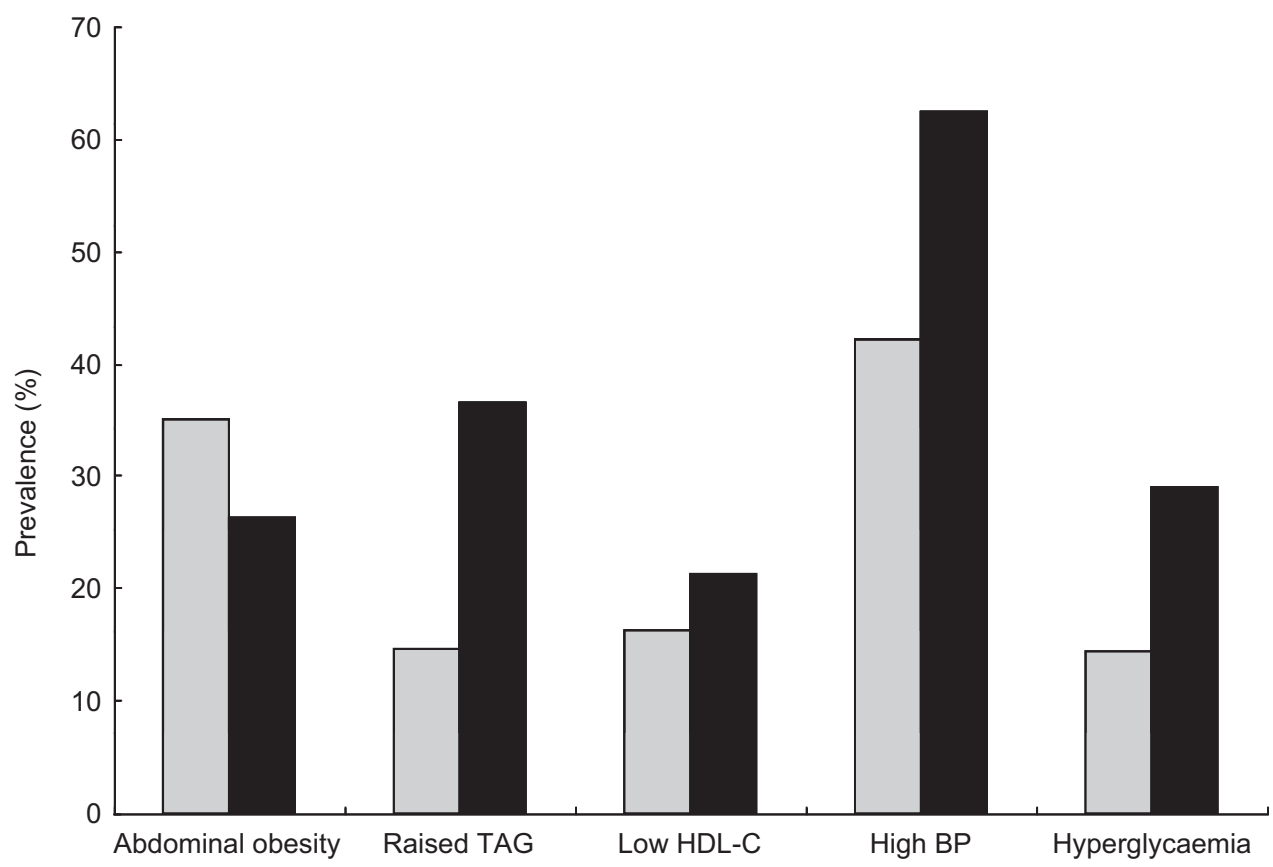

Fig. 2 Prevalence of the metabolic syndrome components (HDL-C, HDL cholesterol; BP, blood pressure), according to the Revised-Adult Treatment Panel (R-ATPIII) definition, among the European adult residents of Luxembourg, ORISCAV-LUX study ( $\square$, women; $\square$, men)

When considering the objective economic status, MetS was significantly more prevalent in subjects below risk of poverty than in those living above it $(P=0.003)$. After age and gender adjustment, the former were still at higher risk $(\mathrm{OR}=1 \cdot 75 ; 95 \% \mathrm{CI} 1 \cdot 21,2 \cdot 53)$ compared with the latter. The prevalence of MetS was lower in subjects living easily within their available resources than in those who reported difficult economic living conditions (24.3\% v. $25 \cdot 9 \%$, respectively). The age- and gender-adjusted OR among the latter group was $1 \cdot 56$ (95\% CI 1·06, 2.28).

\section{Prevalence of metabolic syndrome and lifestyle factors}

The associations between lifestyle factors, such as smoking status, number of cigarettes smoked daily, alcohol consumption and physical activity, and the prevalence of MetS are presented in Table 2. After adjustment for age and gender, current cigarette smokers were at higher risk of developing MetS (OR $=1 \cdot 49$; 95\% CI $1 \cdot 05,2 \cdot 10)$ than non-smokers. Likewise, smoking $>20$ cigarettes/d showed a significant positive association with MetS. The OR for 
Table 1 Prevalence of the metabolic syndrome (MetS) according to socio-economic characteristics among the Europid population of the ORISCAV-LUX study $(n$ 1319)

\begin{tabular}{|c|c|c|c|c|c|}
\hline & \multicolumn{5}{|c|}{ MetS } \\
\hline & $n$ & $\%$ & Adjusted $\mathrm{OR}^{\star}$ & $95 \% \mathrm{Cl}$ & $P$ value \\
\hline Marital status & & & & & 0.67 \\
\hline Married/living with partner ( $n$ 924) & 275 & $28 \cdot 7$ & 1.00 & Ref. & \\
\hline Single (never married) ( $n$ 244) & 32 & $10 \cdot 3$ & $0 \cdot 89$ & $0.55,1.45$ & \\
\hline Divorced/separated ( $n$ 119) & 33 & $26 \cdot 4$ & 0.78 & $0.48,1.25$ & \\
\hline Widowed ( $n$ 32) & 15 & $47 \cdot 8$ & $1 \cdot 23$ & $0.58,2.60$ & \\
\hline Level of education & & & & & $<0 \cdot 0001$ \\
\hline Tertiary (university level) ( $n$ 341) & 62 & $16 \cdot 3$ & $1 \cdot 00$ & Ref. & \\
\hline Secondary ( $n$ 625) & 165 & $24 \cdot 2$ & $1 \cdot 51$ & $1 \cdot 04,2 \cdot 17$ & \\
\hline Primary $(n$ 340) & 123 & $34 \cdot 0$ & $2 \cdot 34$ & $1 \cdot 57,3.48$ & \\
\hline Work status & & & & & $0.037 \ddagger$ \\
\hline Employed ( $n$ 856) & 180 & $19 \cdot 5$ & $1 \cdot 00$ & Ref. & \\
\hline Sick leaver/disabled/unemployed $(n 50)$ & 20 & $37 \cdot 7$ & $1 \cdot 77$ & $0 \cdot 85,3 \cdot 72$ & \\
\hline Retired ( $n$ 170) & 92 & $54 \cdot 0$ & $4 \cdot 15$ & $1 \cdot 15,15 \cdot 02$ & \\
\hline Housewivest & & & & & $<0.0001$ \\
\hline No $(n 520)$ & 78 & $13 \cdot 1$ & $1 \cdot 00$ & Ref. & \\
\hline Yes $(n 160)$ & 61 & $38 \cdot 0$ & $2 \cdot 40$ & $1 \cdot 51,3 \cdot 80$ & \\
\hline Subjective economic status & & & & & 0.024 \\
\hline Easy $(n$ 1006) & 264 & $24 \cdot 3$ & $1 \cdot 00$ & Ref. & \\
\hline Difficult ( $n$ 241) & 69 & $25 \cdot 9$ & $1 \cdot 56$ & $1 \cdot 06,2 \cdot 28$ & \\
\hline Objective economic status & & & & & 0.0030 \\
\hline Above risk of poverty threshold ( $n$ 911) & 231 & $23 \cdot 6$ & $1 \cdot 00$ & Ref. & \\
\hline Below risk of poverty threshold ( $n$ 228) & 73 & $29 \cdot 2$ & $1 \cdot 75$ & $1 \cdot 21,2 \cdot 53$ & \\
\hline
\end{tabular}

Ref., referent category.

*OR adjusted for age and gender.

tOnly women.

$\ddagger$ Significant interaction with age.

Table 2 Prevalence of the metabolic syndrome (MetS) according to lifestyle characteristics among the Europid population of the ORISCAV-LUX study $(n$ 1319)

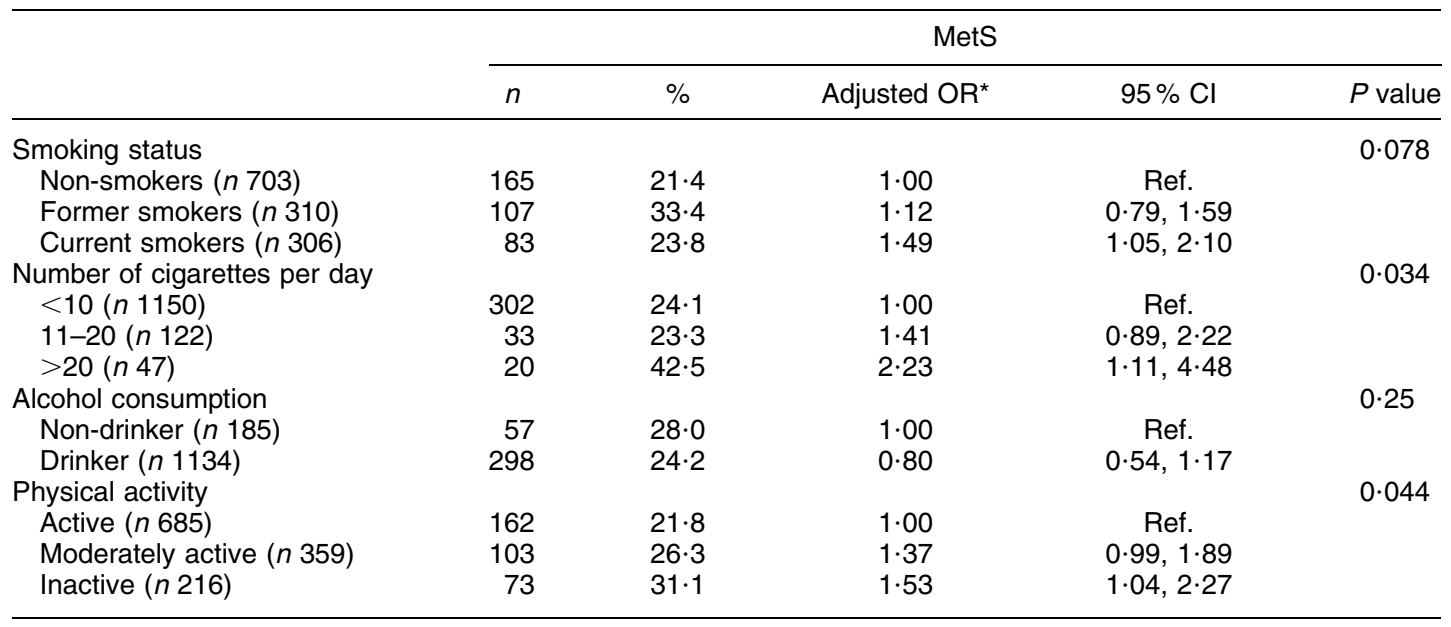

Ref., referent category.

${ }^{*}$ OR adjusted for age and gender.

MetS in moderately active and inactive subjects compared with active subjects was $1 \cdot 37(95 \%$ CI $0 \cdot 99,1 \cdot 89)$ and $1 \cdot 53$ (95\% CI $1 \cdot 04,2 \cdot 27)$, respectively. No association was seen between alcohol intake and MetS.

\section{Prevalence of metabolic syndrome and family medical bistory}

Only diabetes and arterial hypertension were associated with MetS $(\mathrm{OR}=2 \cdot 40 ; 95 \% \mathrm{CI} 1 \cdot 72,3.36$ and $\mathrm{OR}=1 \cdot 61$; $95 \%$ CI $1 \cdot 17,2 \cdot 22$, respectively; Table 3 ).

\section{Prevalence of metabolic syndrome and dietary factors}

A significant association was found between MetS and participants' adherence to recommendations relative to SFA $(P=0.02)$, simple sugars $(P=0.0004)$ and total protein $(P=0 \cdot 006)$. Protein consumption lower than $10 \%$ or higher than $15 \%$ of total energy intake was significantly associated with MetS (OR $=1 \cdot 56$; $95 \%$ CI $1 \cdot 14$, $2 \cdot 15)$. After age and gender adjustment, no MetS-DQI association was observed (Table 4). 
Table 3 Prevalence of the metabolic syndrome (MetS) according to family history of selected medical conditions among the Europid population of the ORISCAV-LUX study ( $n$ 1319)

\begin{tabular}{|c|c|c|c|c|c|}
\hline \multirow[b]{2}{*}{ Family history of selected medical conditions } & \multicolumn{5}{|c|}{ MetS } \\
\hline & $n$ & $\%$ & Adjusted OR* & $95 \% \mathrm{Cl}$ & $P$ value \\
\hline Hypertension & & & & & $0 \cdot 0040$ \\
\hline No $(n 677)$ & 161 & $21 \cdot 5$ & $1 \cdot 00$ & Ref. & \\
\hline Yes ( $n$ 438) & 134 & $28 \cdot 4$ & $1 \cdot 61$ & $1 \cdot 17,2 \cdot 22$ & \\
\hline Diabetes & & & & & $<0.0001$ \\
\hline No $(n 979)$ & 225 & $20 \cdot 8$ & $1 \cdot 00$ & Ref. & \\
\hline Yes $(n 273)$ & 106 & $36 \cdot 5$ & $2 \cdot 40$ & $1 \cdot 72,3 \cdot 36$ & \\
\hline Myocardial infarction & & & & & $0 \cdot 42$ \\
\hline No $(n 965)$ & 247 & $23 \cdot 2$ & $1 \cdot 00$ & Ref. & \\
\hline Yes (n 285) & 93 & $31 \cdot 5$ & $1 \cdot 15$ & $0 \cdot 82,1 \cdot 63$ & \\
\hline Cerebro-vascular accident & & & & & 0.87 \\
\hline No $(n 1035)$ & 255 & $22 \cdot 5$ & $1 \cdot 00$ & Ref. & \\
\hline Yes (n 219) & 82 & $35 \cdot 6$ & $1 \cdot 03$ & $0 \cdot 72,1 \cdot 48$ & \\
\hline
\end{tabular}

Ref., referent category.

${ }^{*}$ OR adjusted for age and gender.

Table 4 Prevalence of the metabolic syndrome (MetS) according to compliance to key dietary recommendations for different food components among the Europid population of the ORISCAV-LUX study ( $n$ 1229)

\begin{tabular}{|c|c|c|c|c|c|c|c|}
\hline \multirow[b]{2}{*}{ Component } & \multirow[b]{2}{*}{ Reference } & \multirow[b]{2}{*}{ Compliance } & \multicolumn{5}{|c|}{ MetS } \\
\hline & & & $n$ & $\%$ & Adjusted OR* & $95 \% \mathrm{Cl}$ & $P$ value \\
\hline Total fat (\%E) & $15-30$ & $\begin{array}{c}\text { Yes }(n 144) \\
\text { No }(n 1060)\end{array}$ & $\begin{array}{r}52 \\
272\end{array}$ & $\begin{array}{l}32 \cdot 5 \\
23 \cdot 7\end{array}$ & $\begin{array}{l}1.00 \\
0.84\end{array}$ & $\begin{array}{c}\text { Ref. } \\
0.55,1 \cdot 29\end{array}$ & 0.43 \\
\hline SFA (\%E) & $<10$ & $\begin{array}{c}\text { Yes }(n 147) \\
\text { No }(n 1057)\end{array}$ & $\begin{array}{r}58 \\
266\end{array}$ & $\begin{array}{l}37 \cdot 5 \\
22 \cdot 9\end{array}$ & $\begin{array}{l}1.00 \\
0.60\end{array}$ & $\begin{array}{c}\text { Ref. } \\
0.39,0.91\end{array}$ & 0.020 \\
\hline PUFA (\%E) & $6-10$ & $\begin{array}{r}\text { Yes }(n 500) \\
\text { No }(n 704)\end{array}$ & $\begin{array}{l}130 \\
194\end{array}$ & $\begin{array}{l}23 \cdot 4 \\
25 \cdot 6\end{array}$ & $\begin{array}{l}1 \cdot 00 \\
1 \cdot 17\end{array}$ & $\begin{array}{c}\text { Ref. } \\
0.87,1.56\end{array}$ & $0 \cdot 30$ \\
\hline MUFA (\%E) & $10-14$ & $\begin{array}{r}\text { Yes }(n 300) \\
\text { No }(n \text { 904) }\end{array}$ & $\begin{array}{r}91 \\
233\end{array}$ & $\begin{array}{l}27 \cdot 7 \\
23 \cdot 7\end{array}$ & $\begin{array}{l}1.00 \\
1.03\end{array}$ & $\begin{array}{c}\text { Ref. } \\
0.73,1 \cdot 45\end{array}$ & $0 \cdot 86$ \\
\hline$n-6: n-3$ ratio & $<5.5$ & $\begin{array}{l}\text { Yes }(n 11) \\
\text { No }(n \text { 1193) }\end{array}$ & $\begin{array}{r}2 \\
322\end{array}$ & $\begin{array}{l}16 \cdot 5 \\
24 \cdot 8\end{array}$ & $\begin{array}{l}1.00 \\
4.91\end{array}$ & $\begin{array}{c}\text { Ref. } \\
0 \cdot 82,29 \cdot 45\end{array}$ & 0.081 \\
\hline Cholesterol (mg/d) & $<300$ & $\begin{array}{c}\text { Yes }(n 551) \\
\text { No }(n \text { 653) }\end{array}$ & $\begin{array}{l}140 \\
184\end{array}$ & $\begin{array}{l}23 \cdot 6 \\
25 \cdot 7\end{array}$ & $\begin{array}{l}1 \cdot 00 \\
1 \cdot 10\end{array}$ & $\begin{array}{c}\text { Ref. } \\
0.81,1 \cdot 49\end{array}$ & 0.53 \\
\hline Total carbohydrates (\%E) & $55-75$ & $\begin{array}{l}\text { Yes }(n 59) \\
\text { No }(n 1145)\end{array}$ & $\begin{array}{r}14 \\
310\end{array}$ & $\begin{array}{l}21 \cdot 5 \\
24 \cdot 9\end{array}$ & $\begin{array}{l}1.00 \\
1.45\end{array}$ & $\begin{array}{c}\text { Ref. } \\
0 \cdot 77,2 \cdot 71\end{array}$ & $0 \cdot 25+$ \\
\hline Simple sugars $(\% \mathrm{E})$ & $<10$ & $\begin{array}{l}\text { Yes }(n 33) \\
\text { No }(n 1171)\end{array}$ & $\begin{array}{r}19 \\
305\end{array}$ & $\begin{array}{l}56 \cdot 8 \\
23 \cdot 9\end{array}$ & $\begin{array}{l}1 \cdot 00 \\
0 \cdot 27\end{array}$ & $\begin{array}{c}\text { Ref. } \\
0 \cdot 13,0.56\end{array}$ & 0.0004 \\
\hline Total protein $(\% \mathrm{E})$ & $10-15$ & $\begin{array}{r}\text { Yes }(n 446) \\
\text { No }(n 758)\end{array}$ & $\begin{array}{r}99 \\
225\end{array}$ & $\begin{array}{l}20 \cdot 6 \\
27 \cdot 2\end{array}$ & $\begin{array}{l}1.00 \\
1.56\end{array}$ & $\begin{array}{c}\text { Ref. } \\
1 \cdot 14,2 \cdot 15\end{array}$ & 0.0060 \\
\hline $\mathrm{Na}(\mathrm{g} / \mathrm{d})$ & $<2$ & $\begin{array}{l}\text { Yes }(n 153) \\
\text { No }(n 1051)\end{array}$ & $\begin{array}{r}45 \\
279\end{array}$ & $\begin{array}{l}27 \cdot 1 \\
24 \cdot 4\end{array}$ & $\begin{array}{l}1.00 \\
0.93\end{array}$ & $\begin{array}{c}\text { Ref. } \\
0 \cdot 62,1 \cdot 34\end{array}$ & $0 \cdot 73$ \\
\hline Fruits and vegetables $(\mathrm{g} / \mathrm{d})$ & $\geq 400$ & $\begin{array}{c}\text { Yes }(n 727) \\
\text { No }(n 477)\end{array}$ & $\begin{array}{l}205 \\
119\end{array}$ & $\begin{array}{l}26 \cdot 5 \\
22 \cdot 2\end{array}$ & $\begin{array}{l}1.00 \\
0.96\end{array}$ & $\begin{array}{c}\text { Ref. } \\
0 \cdot 70,1 \cdot 31\end{array}$ & $0 \cdot 80$ \\
\hline Total fibre $(\mathrm{g} / \mathrm{d})$ & $>25$ & $\begin{array}{r}\text { Yes }(n 510) \\
\text { No }(n 694)\end{array}$ & $\begin{array}{l}143 \\
181\end{array}$ & $\begin{array}{l}26 \cdot 1 \\
23 \cdot 7\end{array}$ & $\begin{array}{l}1.00 \\
1.02\end{array}$ & $\begin{array}{c}\text { Ref. } \\
0 \cdot 76,1 \cdot 37\end{array}$ & $0.90+$ \\
\hline Soluble fibre $(\mathrm{g} / \mathrm{d})$ & $>10$ & $\begin{array}{l}\text { Yes }(n 45) \\
\text { No }(n 1159)\end{array}$ & $\begin{array}{r}16 \\
308\end{array}$ & $\begin{array}{l}33 \cdot 4 \\
24 \cdot 4\end{array}$ & $\begin{array}{l}1 \cdot 00 \\
0 \cdot 89\end{array}$ & $\begin{array}{c}\text { Ref. } \\
0.45,1 \cdot 76\end{array}$ & $0 \cdot 74$ \\
\hline $\begin{array}{l}\text { DQI } \\
\text { Mean } \\
\text { SE }\end{array}$ & $\begin{array}{l}3.01 \\
0.05\end{array}$ & & & & 0.98 & $0 \cdot 90,1 \cdot 07$ & 0.64 \\
\hline
\end{tabular}

$\% \mathrm{E}$, percentage of total daily energy intake; DQI, Diet Quality Index. ${ }^{*} \mathrm{OR}$ adjusted for age and gender.

tInteraction with age is presented.

\section{Metabolic syndrome modelling}

The final model of MetS with respect to the covariates studied demonstrated that age, male gender, primary level of education, physical inactivity, family history of diabetes and hypertension and inadequate total protein intake were significant determinants of MetS after adjustment for all other factors (Table 5). A sensitivity approach was applied to this final model by testing the significance effect of the rejected variables one by one. No additional variable was found to contribute significantly to the model. It is worth mentioning that by adding BMI to the other significant socio-economic, dietary and behavioral factors in the 
Table 5 Final multivariate logistic regression model associating prevalence of the metabolic syndrome (MetS) with demographic, socio-economic, behavioural and dietary characteristics of the Europid population of the ORISCAV-LUX study

\begin{tabular}{|c|c|c|c|}
\hline \multirow[b]{2}{*}{ Characteristic } & \multicolumn{3}{|c|}{ MetS } \\
\hline & $\begin{array}{c}\text { Fully } \\
\text { adjusted OR* }\end{array}$ & $95 \% \mathrm{Cl}$ & $P$ value \\
\hline Age & $1 \cdot 09$ & $1 \cdot 07,1 \cdot 11$ & $<0.0001$ \\
\hline Gender & & & $<0.0001$ \\
\hline Women & 1.00 & Ref. & \\
\hline Men & 3.08 & $2 \cdot 13,4 \cdot 47$ & \\
\hline Level of education & & & 0.030 \\
\hline Tertiary (university level) & $1 \cdot 00$ & Ref. & \\
\hline Secondary & $1 \cdot 34$ & $0.86,2.09$ & \\
\hline Primary & 1.93 & $1 \cdot 18,3 \cdot 15$ & \\
\hline Physical activity & & & $0 \cdot 015$ \\
\hline Active & $1 \cdot 00$ & Ref. & \\
\hline Moderately active & $1 \cdot 49$ & $1 \cdot 00,2 \cdot 21$ & \\
\hline Inactive & 1.94 & $1 \cdot 18,3 \cdot 17$ & \\
\hline Family history of diabetes & & & $<0.0001$ \\
\hline No & $1 \cdot 00$ & Ref. & \\
\hline Yes & $2 \cdot 46$ & $1 \cdot 62,3 \cdot 73$ & \\
\hline $\begin{array}{l}\text { Family history of } \\
\text { hypertension }\end{array}$ & & & $0 \cdot 050$ \\
\hline No & $1 \cdot 00$ & Ref. & \\
\hline Yes & $1 \cdot 44$ & $1 \cdot 00,2 \cdot 08$ & \\
\hline Simple sugars compliance & & & 0.004 \\
\hline Yes & $1 \cdot 00$ & Ref. & \\
\hline No & 0.25 & $0.01,0.63$ & \\
\hline Total protein compliance & & & 0.014 \\
\hline Yes & 1.00 & Ref. & \\
\hline No & 1.59 & $1 \cdot 01,2 \cdot 31$ & \\
\hline
\end{tabular}

Ref., referent category.

${ }^{*}$ OR adjusted for other socio-economic, family history, dietary and lifestyle factors.

model, only age, gender, family history of diabetes and BMI remained significantly associated with MetS (data not shown).

\section{Discussion}

The innovative purpose of the present study was to investigate, for the first time, the epidemiology of MetS in the European population residing in Luxembourg and to discern the potential socio-economic, dietary and behavioural factors that could explain its variability, in order to suggest prevention strategies addressing the real needs of the groups at risk.

The emerging data from European studies suggest that MetS is a common cardio-metabolic disorder, with a prevalence rate ranging from a low $18 \%$ in Italy $^{(25)}$ to a high $38 \%$ in Turkey ${ }^{(26)}$. Nearly $25 \%$ of the Europids in Luxembourg are affected by MetS with significant gender difference. Consistent with previous studies ${ }^{(27)}$, the MetS prevalence rate increased dramatically with age, in both genders. This effect can be largely explained by agerelated rises of blood pressure and glucose level ${ }^{(28)}$. Globally this prevalence rate is comparable to worldwide estimates, although lower than in the USA $(34 \cdot 5 \%)^{(29)}$ and higher than in Australia $(15 \%)^{(30)}$ or China $(17 \%)^{(21)}$.
The prevalence of MetS was significantly higher in our participants with a family history of diabetes and hypertension, regardless of age and gender, and after adjustment for other potential socio-economic, dietary and behavioural factors; hence, this particular subgroup of the population is more susceptible to develop MetS, probably due to genetic predisposition to components of MetS ${ }^{(15)}$.

The prevalence of MetS also differed significantly according to subjective economic status and objective household income independently of age and gender; however, these associations became non-significant in multivariate analyses. An independent MetS-household income association was observed in the USA ${ }^{(9,31)}$, and in French $^{(32)}$ and in Korean women only ${ }^{(33)}$. Marital status had no effect on MetS prevalence when adjusting for age and gender in the present study. By contrast, MetS prevalence differed significantly according to work status; sick leavers, disabled and retired participants were more likely to be affected by MetS than the employed group, irrespective of age and gender. Interestingly, housewives were also more at risk of MetS at any age.

One of the salient findings of the present study concerns the inverse and independent association of education level with MetS. Adjusting for dietary, behavioural and other socio-economic factors did not narrow the differences, suggesting a clear educational disparity in the prevalence of MetS among European adults in Luxembourg. This finding is consistent with previous studies ${ }^{(34,35)}$ that reported pronounced inverse associations between educational level and features of MetS, particularly in women $^{(9,36)}$. Better education definitely facilitates the understanding and acquisition of a healthy lifestyle and hence greater protection against MetS. Moreover, highly educated individuals enjoy better social, psychological and economic support ${ }^{(37)}$. In a wealthy country like Luxembourg, higher education generally leads to a better income and standard of life. Lower education and limited financial resources jointly lead people to select low-cost, unhealthy, energy-dense foods composed of fat, refined grains and added sugar. This type of food favours the development of insulin resistance, hypertriacylglycerolaemia and weight gain ${ }^{(32,38)}$. Another frequently cited correlate with low socio-economic status is the stress that might induce a psychological defeat reaction, which in turn would activate the hypothalamic-pituitary-adrenal axis and trigger cardiovascular risk ${ }^{(33)}$. The psychosocial stress may result from the challenges of daily life, a poor social network and/or uncertainties about future prospects related to social or material disadvantage ${ }^{(39)}$. As a vicious cycle, people in the lowest income categories are most often unemployed and/or unqualified and are bothered by their limited resources, resulting in reduced physical activity and/or stress ${ }^{(32)}$. This in turn favours weight gain and insulin resistance, major precursors of MetS. In spite of the cross-sectional nature of the findings obtained, the negative association between education 
level and MetS is understandable and the hypothesis of reverse causality is not likely to be addressed.

Smoking is known to be highly related to cardiovascular risk and appears to have an adverse effect on several components of MetS, such as hyperglycaemia and high blood pressure ${ }^{(31,40,41)}$. In the present study, a positive dose-response relationship between smoking exposure ( $>20$ cigarettes/d) and MetS was found irrespective of age and gender; however, this association disappeared when adjusting for other confounders. A positive and dose-dependent relationship between the number of cigarettes smoked daily and MetS was found in previous studies $^{(42,43)}$. The exact mechanism of how cigarette smoking increases the risk of MetS remains uncertain, although pharmacological actions of cigarette smoking and nicotine on lipoprotein metabolism and insulin resistance have been demonstrated ${ }^{(44,45)}$.

Regarding alcohol consumption, the literature shows inconsistent findings owing to the complex mechanistic relationship with each component of MetS. Mild to moderate alcohol use has a favourable influence on lipid metabolism, abdominal obesity and glucose regulation ${ }^{(46)}$. In contrast, excessive alcohol consumption causes hypertension $^{(47)}$ and hypertriacylglycerolaemia ${ }^{(48)}$. A recent meta-analysis suggested that 'responsible moderate drinking' places the individual at lower risk of having $\mathrm{MetS}^{(49)}$. No significant association was seen in the present ORISCAV-LUX study, although this finding should be interpreted with caution: the alcohol consumption data were based on self-declaration with the possibility of misclassification of exposure due to under-reporting; additionally, in such a population-based study aiming to observe cardiovascular risk factors, 'social desirability' might push participants to under-report their actual alcohol consumption level. The overall self-reported alcohol drinking during the last 12 months $(5 \cdot 4 \mathrm{~g} / \mathrm{d}$, i.e. half a standard glass/d) was sensibly under-estimated.

The prevalence of MetS varied significantly according to the level of physical activity, showing an independent association after full multivariate adjustment for other factors. Only highly active subjects seemed predominantly protected, suggesting the need to recommend a more active lifestyle for those prone to MetS. The self-reported measures may overestimate the actual physical activity and result in underestimation of the association between moderate activity and the disease outcome ${ }^{(50)}$. In our study, bias related to self-misclassification cannot be excluded and may explain the attenuated moderate activity-MetS association. In spite of methodological shortcomings, selfreported measures remain the most feasible and affordable instruments for global surveillance of physical activity. Another advantage of the IPAQ is that physical activity is expressed in MET-min/week (MET, metabolic equivalent task) rather than energy expenditure $(\mathrm{kJ} / \mathrm{kcal})$, resulting in physical activity estimates independently of body weight. Although comparison between studies is difficult owing to different MetS definitions and dissimilar physical activity evaluation tools, our findings are in agreement with previous studies which showed an inverse MetS-physical activity association ${ }^{(4,51,52)}$. To the best of our knowledge, the present study is the first population-based study that has examined the association between MetS and physical activities according to IPAQ. Another study, based on the Minnesota leisure-time physical activity questionnaire, documented that moderate and vigorous physical activity were both associated with a reduced risk of MetS, independently of age, smoking and high alcohol intake ${ }^{(50)}$. In a study on young adults, sedentary behaviours measured by the number of hours of watching television or playing video/computer games were positively associated with the presence of at least three metabolic risk factors ${ }^{(53)}$. While physical activity was significantly associated with high HDL-C level ${ }^{(54)}$, the adverse effect of inactivity, attributable to reduced energy expenditure, was inversely associated with body weight, blood pressure and $\mathrm{TAG}^{(4)}$.

In the present study, the association of MetS with key individual dietary components was investigated. In addition, a composite measure of diet quality (DQI) was created to evaluate the overall healthfulness of dietary intake, in terms of adherence to the dietary guidelines. Unexpectedly, participants who were non-compliant with the simple sugars and SFA guidelines showed significantly lower odds of having MetS, regardless of their age and gender. The confirmed association between simple sugars and MetS in the fully adjusted model may be explained by the reverse causality inherent to the cross-sectional nature of the study. It seems that suffering from dyslipidaemia or diabetes may significantly encourage the participants to limit their intake of SFA or simple sugars. In addition, the limited number of subjects in the compliant category (thirty-three cases, $2 \cdot 7 \%$ ) may underpowered to infer about the harmful effect of simple sugars on MetS. An exploratory analysis showed that participants with diabetes and lipid disorders did better in adhering to the recommendations than those free of these pathologies. Moreover, a significant proportion of participants having MetS were currently on one or more diets, for example to lower their cholesterol, sugar intake, blood pressure or lose weight (data not shown).

Another striking result of the ORISCAV-LUX study was the persistent independent association between MetS and total protein intake, even after adjustment for age, gender, education, socio-economic factors, smoking, physical activity, family medical history and other dietary factors (including SFA). These findings are, at least in part, in agreement with the prospective Japanese-Brazilian Diabetes Study, in which specifically red meat consumption (major source of protein and fat) was associated with an almost fivefold increase in the risk of MetS in men ${ }^{(55)}$. This nutrient-specific observation requires further in-depth investigation regarding the type of protein (for example, animal red meats) and the potential confounding role of total fat and its components 
(SFA, MUFA and PUFA). Considering the DQI, no association was seen with MetS after adjusting for potential confounding factors, suggesting that the overall quality of diet had no significant impact on the prevalence of MetS in our studied population.

When considering BMI among other potential confounders in the final model (data not shown), only age, gender and family history of diabetes remained independently associated with the high prevalence of MetS, suggesting that BMI is the most sensitive marker among associated factors for MetS. This finding is consistent with results from US and Korean adults, in which the BMI was shown to be a strong predictor for $\mathrm{MetS}^{(31,56)}$.

The present study is characterized by several strong points. The ORISCAV-LUX is based on a recent nationwide sample of Luxembourg adult residents ${ }^{(18)}$. A detailed study of non-participants showed comparable demographic and clinical characteristics of participants and non-participants, hence providing population-representative prevalence estimates $^{(22)}$. Nevertheless, a number of limitations should be recognized. First, the cross-sectional design has inherent drawbacks and precludes causal inferences, notably regarding the MetS-simple sugars association. Second, the analyses were based on the Europid population; our results may therefore not apply to other ethnic groups. Third, as in most epidemiological studies, the risk exists for incomplete adjustment for latent confounders, such as psychosocial factors. Finally, evaluation of tobacco consumption, alcohol use, physical activity and food habits was based on selfreported information. Although the participants completed the auto-administered questionnaire with the help and supervision of well-trained staff, the possibility of under- or over-reporting cannot be excluded. This might lead to a selective misclassification of high-risk individuals which could blur the potential association.

In summary, from a public health standpoint, our findings suggest that male gender, age, low education, family history of diabetes and hypertension as well as specific behavioural and lifestyle factors, such as physical inactivity and inadequate protein intake, account for the disparities observed in MetS prevalence rates among the studied population. The multiplicity of factors contributing to MetS highlights the potential interactions that occur at both individual and behavioural levels to produce the condition. MetS does not develop overnight, but rather becomes established over years of overlapping dietary, behavioural and inherited risk factors. These findings support the need for a comprehensive approach in clinical and community settings to promote healthier habits.

\section{Acknowledgements}

The work was supported by a research grant from the National Fund of Research (Fond National de Recherche; project MSF, 784844, BM). The authors declare that they have no competing interest. A. Alkerwi was involved in the conception and design of the ORISCAV-LUX survey, coordinated the field data collection, conceived the present research, contributed to data analyses and drafted the manuscript. A.-F.D. conducted the statistical analyses and discussion of the results. N.S. participated in the statistical analyses. A. Albert provided critical reviews of the manuscript and intellectual content. M.G. provided expertise and oversight throughout the process. All authors reviewed drafts and approved the final version of the manuscript. The ORISCAV-LUX study was made possible by the people who agreed to participate and the financial support of government (Ministry of Health and Ministry of Research).

\section{References}

1. Hanson RL, Imperatore G, Bennett PH et al. (2002) Components of the 'metabolic syndrome' and incidence of type 2 diabetes. Diabetes 51, 3120-3127.

2. Laaksonen DE, Lakka HM, Niskanen LK et al. (2002) Metabolic syndrome and development of diabetes mellitus: application and validation of recently suggested definitions of the metabolic syndrome in a prospective cohort study. Am J Epidemiol 156, 1070-1077.

3. Pyorala M, Miettinen H, Halonen P et al. (2000) Insulin resistance syndrome predicts the risk of coronary heart disease and stroke in healthy middle-aged men: the 22-year follow-up results of the Helsinki Policemen Study. Arterioscler Thromb Vasc Biol 20, 538-544.

4. Ford ES, Kohl HW 3rd, Mokdad AH et al. (2005) Sedentary behavior, physical activity, and the metabolic syndrome among US adults. Obes Res 13, 608-614.

5. Liese AD, Mayer-Davis EJ \& Haffner SM (1998) Development of the multiple metabolic syndrome: an epidemiologic perspective. Epidemiol Rev 20, 157-172.

6. Carnethon MR, Loria CM, Hill JO et al. (2004) Risk factors for the metabolic syndrome: the Coronary Artery Risk Development in Young Adults (CARDIA) study, 1985-2001. Diabetes Care 27, 2707-2715.

7. Yoo S, Nicklas T, Baranowski T et al. (2004) Comparison of dietary intakes associated with metabolic syndrome risk factors in young adults: the Bogalusa Heart Study. $\mathrm{Am} \mathrm{J}$ Clin Nutr 80, 841-848.

8. Fappa E, Yannakoulia M, Pitsavos C et al. (2008) Lifestyle intervention in the management of metabolic syndrome: could we improve adherence issues? Nutrition 24, 286-291.

9. Loucks EB, Magnusson KT, Cook S et al. (2007) Socioeconomic position and the metabolic syndrome in early, middle, and late life: evidence from NHANES 1999-2002. Ann Epidemiol 17, 782-790.

10. Loucks EB, Rehkopf DH, Thurston RC et al. (2007) Socioeconomic disparities in metabolic syndrome differ by gender: evidence from NHANES III. Ann Epidemiol 17, 19-26.

11. Lucove JC, Kaufman JS \& James SA (2007) Association between adult and childhood socioeconomic status and prevalence of the metabolic syndrome in African Americans: the Pitt County Study. Am J Public Health 97, 234-236.

12. Zhu S, St-Onge MP, Heshka S et al. (2004) Lifestyle behaviors associated with lower risk of having the metabolic syndrome. Metabolism 53, 1503-1511.

13. Kim MH, Kim MK, Choi BY et al. (2005) Educational disparities in the metabolic syndrome in a rapidly changing society - the case of South Korea. Int J Epidemiol 34, 1266-1273. 
14. Xu Y (2007) The characteristics of living and behavioral factors in Chinese patients with metabolic syndrome. J Health Sci 53, 84-91.

15. Erem C, Hacihasanoglu A, Deger O et al. (2008) Prevalence of metabolic syndrome and associated risk factors among Turkish adults: Trabzon MetS study. Endocrine 33, 9-20.

16. Panagiotakos DB, Pitsavos C, Chrysohoou C et al. (2004) Impact of lifestyle habits on the prevalence of the metabolic syndrome among Greek adults from the ATTICA study. Am Heart J 147, 106-112.

17. Directorate of Health, Ministry of Health (2006) Statistiques des causes de décès (National Statistics of all causes of death). Luxembourg: Direction de la Santé; available at http:// www.sante.public.lu/statistiques-causes-deces/index.html

18. Alkerwi A, Sauvageot N, Donneau AF et al. (2010) First nationwide survey on cardiovascular risk factors in GrandDuchy of Luxembourg (ORISCAV-LUX). BMC Public Health 10, 468.

19. Alberti KG, Eckel RH, Grundy SM et al. (2009) Harmonizing the metabolic syndrome: a joint interim statement of the International Diabetes Federation Task Force on Epidemiology and Prevention; National Heart, Lung, and Blood Institute; American Heart Association; World Heart Federation; International Atherosclerosis Society; and International Association for the Study of Obesity. Circulation 120, 1640-1645.

20. Alkerwi A, Donneau AF, Sauvageot N et al. (2011) Prevalence of the metabolic syndrome in Luxembourg according to the Joint Interim Statement definition estimated from the ORISCAV-LUX study. BMC Public Health 11, 4.

21. Liu J, Grundy SM, Wang W et al. (2006) Ethnic-specific criteria for the metabolic syndrome: evidence from China. Diabetes Care 29, 1414-1416.

22. Alkerwi A, Sauvageot N, Couffignal S et al. (2010) Comparison of participants and non-participants to the ORISCAV-LUX population-based study on cardiovascular risk factors in Luxembourg. BMC Med Res Methodol 10, 80 .

23. Grundy SM, Cleeman JI, Daniels SR et al. (2005) Diagnosis and management of the metabolic syndrome. An American Heart Association/National Heart, Lung, and Blood Institute Scientific Statement. Executive summary. Cardiol Rev 13, 322-327.

24. World Health Organization (2003) Diet, Nutrition and the Prevention of Chronic Diseases. WHO Technical Report Series no. 916. Geneva: WHO

25. Mannucci E, Monami M, Bardini G et al. (2007) National Cholesterol Educational Program and International Diabetes Federation diagnostic criteria for metabolic syndrome in an Italian cohort: results from the FIBAR Study. J Endocrinol Invest 30, 925-930.

26. Can AS \& Bersot TP (2007) Analysis of agreement among definitions of metabolic syndrome in nondiabetic Turkish adults: a methodological study. BMC Public Health 7, 353.

27. Hildrum B, Mykletun A, Hole T et al. (2007) Age-specific prevalence of the metabolic syndrome defined by the International Diabetes Federation and the National Cholesterol Education Program: the Norwegian HUNT 2 study. BMC Public Health 7, 220.

28. Alexander CM, Landsman PB \& Grundy SM (2008) The influence of age and body mass index on the metabolic syndrome and its components. Diabetes Obes Metab 10, 246-250.

29. Ford ES \& Giles WH (2003) A comparison of the prevalence of the metabolic syndrome using two proposed definitions. Diabetes Care 26, 575-581.

30. Adams RJ, Appleton S, Wilson DH et al. (2005) Population comparison of two clinical approaches to the metabolic syndrome: implications of the new International Diabetes Federation consensus definition. Diabetes Care 28, $2777-2779$.
31. Park YW, Zhu S, Palaniappan L et al. (2003) The metabolic syndrome: prevalence and associated risk factor findings in the US population from the Third National Health and Nutrition Examination Survey, 1988-1994. Arch Intern Med 163, 427-436.

32. Dallongeville J, Cottel D, Ferrieres J et al. (2005) Household income is associated with the risk of metabolic syndrome in a sex-specific manner. Diabetes Care 28, 409-415.

33. Park MJ, Yun KE, Lee GE et al. (2007) A cross-sectional study of socioeconomic status and the metabolic syndrome in Korean adults. Ann Epidemiol 17, 320-326.

34. Lidfeldt J, Nyberg P, Nerbrand C et al. (2003) Sociodemographic and psychosocial factors are associated with features of the metabolic syndrome. The Women's Health in the Lund Area (WHILA) study. Diabetes Obes Metab 5, 106-112.

35. Goyal A, Bhatt DL, Steg PG et al. (2010) Attained educational level and incident atherothrombotic events in low- and middle-income compared with high-income countries. Circulation 122, 1167-1175.

36. Wamala SP, Lynch J, Horsten M et al. (1999) Education and the metabolic syndrome in women. Diabetes Care 22, 1999-2003.

37. Winkleby MA, Jatulis DE, Frank E et al. (1992) Socioeconomic status and health: how education, income, and occupation contribute to risk factors for cardiovascular disease. Am J Public Health 82, 816-820.

38. Drewnowski A \& Specter SE (2004) Poverty and obesity: the role of energy density and energy costs. Am J Clin Nutr 79, 6-16.

39. Gallo LC \& Matthews KA (2003) Understanding the association between socioeconomic status and physical health: do negative emotions play a role? Psychol Bull 129, 10-51.

40. Dzien A, Dzien-Bischinger C, Hoppichler F et al. (2004) The metabolic syndrome as a link between smoking and cardiovascular disease. Diabetes Obes Metab 6, 127-132.

41. Retnakaran R, Hanley AJ, Connelly PW et al. (2005) Cigarette smoking and cardiovascular risk factors among Aboriginal Canadian youths. CMAJ 173, 885-889.

42. Masulli M \& Vaccaro O (2006) Association between cigarette smoking and metabolic syndrome. Diabetes Care 29, 482; author reply 482-483.

43. Oh SW, Yoon YS, Lee ES et al. (2005) Association between cigarette smoking and metabolic syndrome: the Korea National Health and Nutrition Examination Survey. Diabetes Care 28, 2064-2066.

44. Facchini FS, Hollenbeck CB, Jeppesen J et al. (1992) Insulin resistance and cigarette smoking. Lancet 339, 1128-1130.

45. Nakanishi N, Takatorige $\mathrm{T} \&$ \& Suzuki K (2005) Cigarette smoking and the risk of the metabolic syndrome in middleaged Japanese male office workers. Ind Health 43, 295-301.

46. Koppes LL, Dekker JM, Hendriks HF et al. (2005) Moderate alcohol consumption lowers the risk of type 2 diabetes: a meta-analysis of prospective observational studies. Diabetes Care 28, 719-725.

47. Xin X, He J, Frontini MG et al. (2001) Effects of alcohol reduction on blood pressure: a meta-analysis of randomized controlled trials. Hypertension 38, 1112-1117.

48. Kato I, Kiyohara Y, Kubo M et al. (2003) Insulin-mediated effects of alcohol intake on serum lipid levels in a general population: the Hisayama Study. J Clin Epidemiol 56, 196-204.

49. Alkerwi A, Boutsen M, Vaillant M et al. (2009) Alcohol consumption and the prevalence of metabolic syndrome: a meta-analysis of observational studies. Atherosclerosis 204, 624-635.

50. Rennie KL, McCarthy N \& Yazdgerdi S (2003) Association of the metabolic syndrome with both vigorous and moderate physical activity. Int J Epidemiol 32, 600-606.

51. Irwin ML, Ainsworth BE, Mayer-Davis EJ et al. (2002) Physical activity and the metabolic syndrome in a tri-ethnic sample of women. Obes Res 10, 1030-1037. 
52. Rennie KL, Hemingway H, Kumari M et al. (2003) Effects of moderate and vigorous physical activity on heart rate variability in a British study of civil servants. $\mathrm{Am} \mathrm{J}$ Epidemiol 158, 135-143.

53. Gustat J, Srinivasan SR, Elkasabany A et al. (2002) Relation of self-rated measures of physical activity to multiple risk factors of insulin resistance syndrome in young adults: the Bogalusa Heart Study. J Clin Epidemiol 55, 997-1006.
54. Pitsavos C, Panagiotakos D, Weinem M et al. (2006) Diet, exercise and the metabolic syndrome. Rev Diabet Stud 3, 118-126.

55. Damiao R, Castro TG, Cardoso MA et al. (2006) Dietary intakes associated with metabolic syndrome in a cohort of Japanese ancestry. Br J Nutr 96, 532-538.

56. Park HS, Oh SW, Cho SI et al. (2004) The metabolic syndrome and associated lifestyle factors among South Korean adults. Int J Epidemiol 33, 328-336. 